\title{
Teaching Chinese Students: Understanding Their Public Sector Paradigm
}

Cynthia Conrad, University of New Haven, USA

Charles Coleman, University of New Haven, USA

\begin{abstract}
Teaching Chinese students in an American university can be both challenging and rewarding. Cultural and language differences can lead to some superficial confusion and interpretational problems. However, the vast differences in the ways Chinese students view the role of the public sector, as compared to the US, can mean that the instructors and students are looking at the same concepts from vastly different perspectives. Expectations regarding the role of government and the structure of authoritative organizations are so dissimilar as to prevent a commonality on which to base communication. The Chinese view and practice of public administration vary greatly from that of the United States. In China, centralized management and policy-making are the rule, where in the US, the separation of power and administration exist endemically. Because of these differences, one could posit that Chinese students, participating in a Masters of Public Administration program in the US, should come away with unique views of public management in the United States as well as how similar practices compare in China. A survey recently completed by the Department of Public Management at the University of New Haven found that often Chinese students come away from the MPA experience with confusion about, concerns for the need or efficiency of a decentralized government and still believe a highly centralized government is the best model. Reconciling these beliefs with the fundamentals of the discipline of Public Administration, as practiced in the United States, presents some serious challenges to instructors.

The University of New Haven, Master of Public Administration program, has hosted a number of Chinese students over the past few years. At the completion of their time at UNH, students completed an essay discussing what they had learned from their courses and practical experiences in the program. This paper is a review of those responses and their implications for how Chinese students view US public administration. The authors also discuss possible explanations for the very different views on the role of the public sector and the possible ramifications for future public servants in China.
\end{abstract}

Keywords: Chinese Students; Chinese public administration instruction; centralized government

\section{INTRODUCTION}

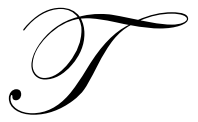

he Master's in Public Administration Program (MPA) at the University of New Haven has a history of attracting students from around the world. They provided an interesting and valuable perspective to their fellow American students and the MPA faculty, as well as providing an excellent research opportunity. Several years ago, the University of New Haven began offering the MPA Program directly to several provinces in the People's Republic of China. Cohorts of students from both Shandong Province and the Guangxi Autonomous Region have attended the program both in China and in the United States. These individuals have been mid-career students who are regional or municipal administrators in their country. They take approximately half of their MPA courses in China and the balance in the US at the University of New Haven. This paper is the result of a study that utilized students from a Guangxi cohort who completed their MPA at the University of New Haven.

The Guangxi Autonomous Region is located in southern China, bordered by Vietnam and has a population of almost approximately forty five million. Its capital is Nanning and the region produces agricultural products. Its 
population is predominantly Han Chinese but it has a large percentage of minorities as well. The students in the Guangxi cohort were all mid level and upper mid level regional officials. They worked for the different divisions of the Guangxi regional government in such capacities as Division Chief, Guangxi Regional Department of Justice, Deputy Division Chief, Guangxi Research Institute of Agriculture, and Principle Officer, Guangxi Police Bureau. Overall, they were a very talented and professional group that was very similar to the traditional American MPA student body at the University of New Haven.

This particular group of Guangxi students arrived at the University in the summer of 2002 and received additional English language instruction prior to starting the session. The MPA at the University of New Haven consists of nine required course and five concentration or elected courses. During their first session, the Chinese students attended all four classes together in a cohort format. The courses were basic courses in public administration and economics. The syllabi and texts used were the same as for the traditional MPA students.

These courses were important as they served as an introduction to the American system of higher education. Students were encouraged to ask questions, do independent work, and consult with the instructor when they had a problem. From discussions with the students, it was very apparent that they were interested in economic development issues in general and courses that would help them specifically when they returned to China. Therefore, in the winter and spring sessions, the students were allowed to choose two courses as electives in addition to the two courses as a cohort. One of the required, cohort courses was an economic development course taught by an area practitioner that included talks on the subject by several local officials. The students seemed to appreciate the combination of cohort and elective courses.

As a part of their courses, the students attended city council meetings, school board meetings, and met many local and state officials, including the governor of Connecticut. They also attended many social and cultural gatherings and participated in all university functions. They experienced American holidays, several civic groups, and many individual faculty and staff members hosted spent Thanksgiving with an American family. The Provost's Office at the University was especially forthcoming with resources to provide the Chinese students with an introduction to American educational, political, and cultural life.

As a culminating experience, the Chinese students completed a professional internship during their second summer of instruction, in addition to attending a Public Administration Seminar course. The internship matched, as closely as possible, their position in the Guangxi government. Internships were in such organizations as the New Haven Superior Court, several Boards of Education, the Quinnipiac Valley Health Department, the Connecticut Agricultural Experimental Station, and several area municipal governments. A requirement for credit for the internship course was a report detailing what they learned. The requirement for the Public Administration Seminar course was a narrative paper describing what they had learned because of their experiences at the University of New Haven and how it would or would not influence their practice of public service in China. The resulting data from these reports shows that although the Chinese students observed and learned from their classes and internships, the fact remains that their observations were from a different perspective than that of the average US student of public administration. Evidently because they come from a collectivist but hierarchical society that places great emphasis on respect of authority, Chinese students take a much more passive position in learning in graduate classes. Even so, they arrived socialized and fully formed ideologically. Because of the stark difference in the Chinese students' views of the role and form of government, the question arises as to how much of what they learned was actually relevant and useful to them, once they returned to their public service positions in China.

In the face of that question, this paper explores the differences in governmental paradigms between the common American views and those of the Chinese students hosted by the University of New Haven. Perhaps, a better understanding of their views and models can help professors in United States universities to address the public administrative approach needed to give useful and effective skills to Chinese students.

\section{BACKGROUND}

The driving force behind the increasing numbers of Chinese students studying public administration in the United States is the paradigm shift that has been happening in the public sector in China. "Over the past two 
decades, China has promoted the transition from a traditional planned economy to a market economy, but has tried to make this transition with poor administrative efficiency and large government." As the economy and global role of China have expanded and changed, the need for more evolved public administration has become evident. The Chinese have had to equilibrate their regulatory processes, at least those dealing with external entities, with those of the rest of the capitalist world in order to retain trade partnerships. The resulting wave of reform has tried to move the management and regulation of the Chinese public sector away from the "rule of man" and toward the "rule of law." In other words, the goals of the reforms are to take away the kind of individualized, non-standardized, and perhaps uneven administration and management that had gone on under the totalitarian, communist state and replace it with codified regulations administered uniformly. Such a change is a de facto requirement for economic growth. Investors, particularly foreign, do not have confidence in investing or working in a country in which the regulations are applied capriciously.

There has been gradual, evolutionary change in China for the last forty years or so. Major changes introduced in their administrative system include decentralization of decision making power, separation of economic enterprises from administrative agencies, simplification of administrative structures, professionalization of public administration training and education and establishing a civil service to replace the old cadre system.

The Chinese government officially adopted the "Regulations on State Functionaries" in October 1993, which was analogous to the Pendleton Act in the United States, in that it created a civil service system in China. Chinese public servants have had to embrace a new, regulated, and codified public service environment, without managerial capriciousness. For many though, change has been quite slow, requiring many public managers to seek retraining. As a result, many have attended foreign universities to learn the theories and practices behind public administration in other countries. For many, internalizing the paradigm shift is not as easy as one might think. In some cases, the fundamental views of the role of government may stand in the path of adaptation to the notion of standardized regulations or any other reforms to their public sector.

A stark difference between Chinese students and those of western universities is often the fact that central to the Chinese views of government seems to be the notion that centralized government is always better than any kind of decentralized systems, such as the federal system in the United States. Public administration as a discipline, has long operated in the assumption that decentralized government was the better choice for the most democratic and responsive form of government. In the United States, this view is a direct result of our colonial experience, at which time our people experienced subjugation to a king and determined the lack of representative government required a revolutionary response. Conversely, the history of China has had a vast historical legacy of centralized government, from the times of warlords and divine right emperors to the centralized communist government, which emerged in the twentieth century. Within the context of Chinese history, a centralized government appears to be commensurate with stability and peace, hence the preference. The two views of the preferred form of government are absolute, diametric opposites.

\section{Perceptions Of American Public Administration}

As a requirement to complete their coursework at UNH, students wrote essays, answering several questions about their views and perceptions of their educational experience and the US in general. These essays were effectively open-ended surveys asking each student about their views on some basic areas of public administration in the United States. The authors of this paper used content analysis to collect data and check reliability among the responses. The following findings are the result of that analysis.

The questions asked of the students in their final essays were: 1) had they learned skills and information useful to them in China? 2) Was centralized government a better model? 3) Was decentralized government a better model? 4) Was transparency crucial to public administration? 4) Was US participatory government a better model? 5) Was it better to rely on laws than personality in public administration, as they had seen in the US? 5) Was education better in the United States than China? 6) Was transportation better in the United States than China? 6) Were US economic policies better than those of China 6) were? 7) Was Social Security specifically a good idea? 8) Can the US learn from China in terms of public administration? 9) Can China learn from the US in terms of Public 
Administration? The students responded to these questions in their own words. Content analysis allowed the authors of this paper to tabulate responses in terms of yes or no.

\section{FINDINGS FROM ANALYSIS}

Examination of the student responses gleaned by content analysis, showed the following responses. Chart 1 shows the comparative responses of each question. The discussion that follows will provide further insight to each of the questions.

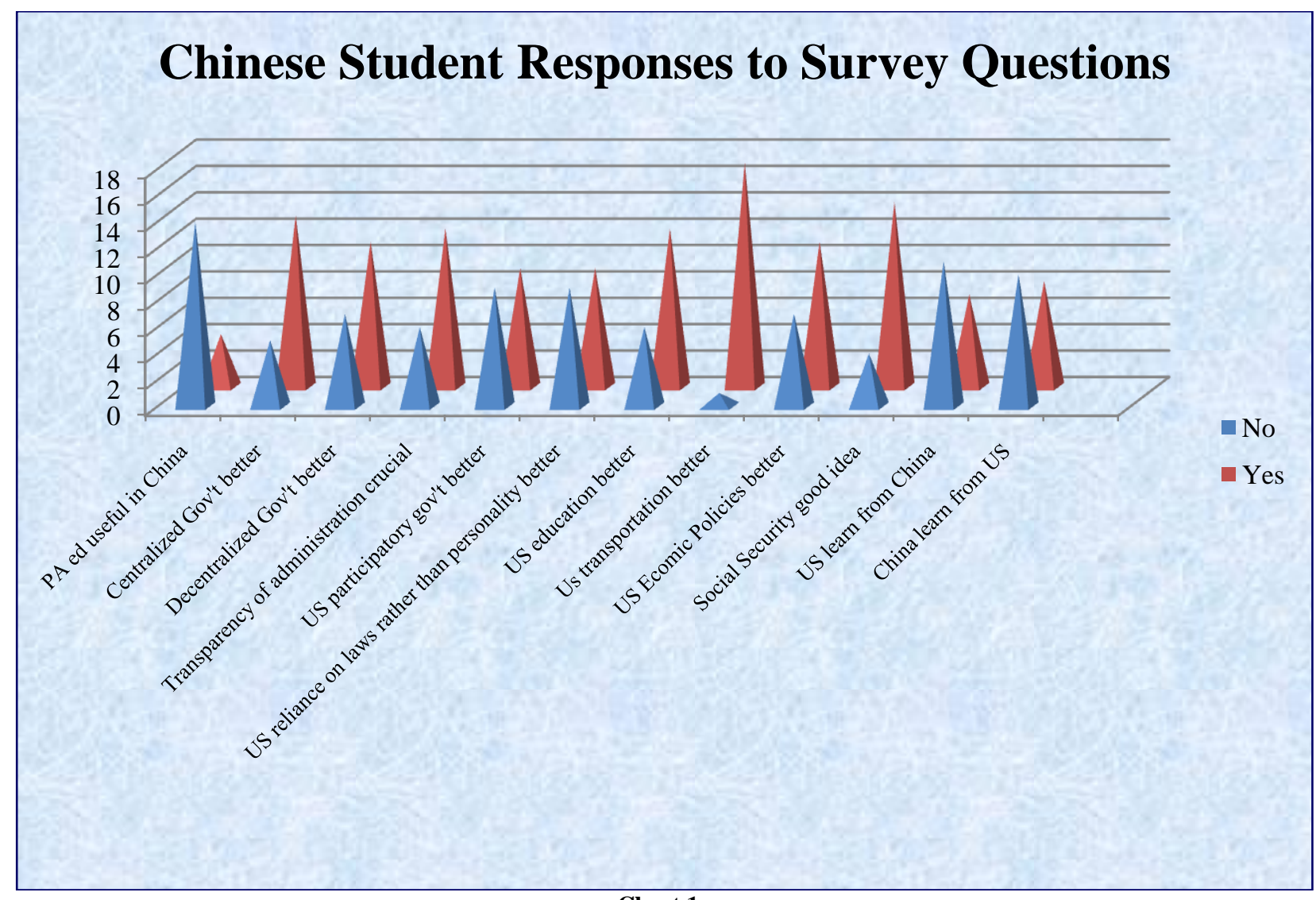

Chart 1

As we can see from these overall finding the Chinese students felt that in many cases United States was an advantage. In other areas, they felt that the Chinese system was preferable. Unfortunately, it seemed these students did not feel that their public administration education was going to be especially useful to them when they return to China. In fact, specific responses to the question whether or not there education in public administration amendments was going to be useful to the China, only for us that yes it would be useful to them were 14 signal was not would be useful to them when they return to China. Considering most of these individuals work back of administrators in their home country and working mid-level management jobs in all levels of government the fact that they felt that their educational experience here was not helpful would seem to be particularly.

Concerning how the students felt about centralized or decentralized government, it seems that their preference was toward centralized. As they mentioned in the comments they felt that centralized government was much better able to deal with emergencies and threats from outside. In fact, their comments showed a general unease 
with the possibility of having a decentralized government address a serious emergency. When asked if centralize government was better than the centralize government 13 of the students responded yes were only five said no.

The issue governmental transparency in policymaking and implementation were covered extensively in the curriculum of the Masters of Public Administration program, which these students attended. The faculty asked the students to observe transparency in the public meetings they attended and in the ratings and case studies provided by their coursework. All such material had a distinctly American perspective. The students felt that transparency of government was a good thing. It is evidently not common in China. In the survey data, six of the students said that transparency was not good whereas 14 said that it is a good aspect of governmental operation area.

It is an interesting finding that the students split evenly on the questions of whether or not participatory government was better and whether or not reliance on laws rather than personalities was better in policymaking. In answering these questions, students said yes in nine cases and no in nine cases to both questions, to whether or not citizen participation and reliance on laws and codes were best.

\section{Interesting Specific Observations From Surveys}

Evidently, volunteering for government service is not a common occurrence in China. Several students mentioned it as something they saw for the first time in the US and seemed unclear to the motivations of the individuals involved.

Legal protection for disabled individuals and improved access for the mobility impaired were novel ideas to many students, according to their essays. No laws exist that may be analogous to the Americans with Disabilities Act of the US.

After attending a public, town meeting in which citizens expressed ideas and elected officials took notice, students commented that such an experience was new to many of the students. Several who observed a meeting in Hamden, Connecticut indicated that it seemed to make a large impression.

The idea of a part time graduate program, where students could attend at night while working full time, seemed to appeal to several of the students. They thought such an approach would work well in China and would allow many more people to seek graduate education. Evidently, such programs are not common in China.

\section{Important Quotes From Students' Essays}

Regarding the concept of governmental centralization, the students provided some very interesting comments that provide insight into their ideas of governmental paradigms.

One student related:

China is an integrated governmental system, all provinces and municipal areas have the same government department classification, share the same governmental function, the uniformity of the system help to ensure the rapid communications among different regions and different levels of government, help laws and policies enforcement, and have the obvious advantage to concentrate power and strength of the nation to implement the urgent and critical tasks, for example, to control the nationwide disease problem.

Extolling much the same sentiment, other students stated:

China is a country with more high-centralized power in central government. It is very easy to centralize the strength of this system for a certain matter. For example, the central government could centralize all its strength to handle emergencies or disasters. I think this may be an advantage in public administration as it relates to dealing with emergencies and other important matters.

Due to the decentralization of public administration, the functions of government are becoming clearer and clearer; administrative obligations are further fulfilled; centralization, monopolization, and responsibility evasion have been 
avoided and reduced. Meanwhile as a result of administrative decentralization, the organizations of public administration can check and balance each other.

In China, government system is set up according to the principle of the unity of democracy and centralization. The central government can command and control the local governments and make them carry out central government's policies and decisions. If local governments do not fulfill their obligations, central government has rights to reorganize them. It is proved that central government's authority is propitious for the unification of the government order of central government.

Considering citizen participation is decision-making or governmental action, one student made the following remarkable statement, showing how he or she views the role of leaders in policymaking:

In China, when governments make decisions or work out policies, they do sometimes solicit opinions from the general public or consult some experts, but for most of the time, leaders play a very important role in policy making.

When discussion the influence of laws and codes in comparison to the individual decision making of officials, in other words the preferred reliance on laws and regulations, one student stated his or her perception of the contrast:

In America, there are many laws and regulations, these laws and regulations must be abided. Doing everything is strict procedure and every civil servant easily does daily work according to the laws and regulations. But, in China, because of many factors, management usually depends heavily on the human's will, especially upper leaders' will, so in the public administration, usually the factors of person are more important than laws or regulations.

\section{CONCLUSION}

All of the above statements as well as the aggregate findings provide better understanding of this group's views of the role of citizens and laws in public administration in the United States as compared to China. Clearly, there are some fundamental differences. Those differences may affect the impressions and interpretations of knowledge that US educators may provide Chinese students as we teach them the fundamentals and tenets of public administration, from the western perspective. Perhaps educators of Chinese students, who study public administration, should make sure to consider the differences that exist between the assumptions of the role of government in the United States and those analogous assumptions in China. In this way, the material and curriculum may be better focused and therefore more useful for Chinese students who return to China to continue their public service careers.

\section{ABOUT THE AUTHORS}

Dr. Cynthia Conrad is an Associate Professor of Public Management. Her position is in the Department of Management, in the School of Business at the University of New Haven. Dr. Conrad holds a Ph.D. in Administration (Public Health) from the University of Texas at Arlington as well as a Master of Arts in Political Science also from the University of Texas at Arlington, and a Bachelor of Science in Political Science from Southern Illinois University. Previous academic positions for Dr. Conrad were in part, Assistant Professor of Public Administration and Economics at the University of Hartford, Visiting Assistant Professor of Economics at Penn State University, and Assistant Professor of Public Administration at the University of Texas at San Antonio. Counted among Dr. Conrad's prior professional positions are transportation planner and public information officer for the City of Dallas, Texas and Transportation Data Analyst for the City of Fort Worth, Texas. Dr. Conrad serves on the editorial board and is an ad hoc reviewer for numerous academic journals, and has published fourteen manuscripts in peer-reviewed academic journals, including Journal of Health and Human Services Administration, International Journal of Public Administration, Public Administration Review, Social Science Quarterly, Internet Medical Journal, and The Journal of Dental Hygiene, She has received several grants in support of her research into issues of health economics and finance, or public health. 
Mr. Coleman received his B.A. from the University of Maryland, his Masters of Public Administration from West Virginia University and did doctoral work at the University of Pittsburgh in Public Administration. Mr. Coleman received a doctoral level certificate in Educational Research Methodology from the University of Pittsburgh. Charles N. Coleman is Chairman of the Public Management Department at the University of New Haven. He is also the advisor for the MBA Program. Mr. Coleman has worked for the Federal government, county government, and municipal government. He serves as a consultant to several local municipalities on budgetary and personnel management issues. Mr. Coleman is active in community activities and recently served on the local School Board.

\section{REFERENCES}

1. Guangxi Statistical Yearbook (2001), China Statistics Press, 2001.

2. Guirong Mao, On Governmental Reform in China: Two Suggestions from Japanese Experiences, Chinese Public Administration Review, Vol.2, No 1, pp 20-36, 2003.

3. Tom Liou, Koutsal, Issues and lessons of Chinese civil service reform, Public Personnel Management, Vol. 26, 1997.

4. Tsao, King, Chinese Pulic Administration: Change with Continuity during Political and Economic Development, Public Administration Review, Vol. 55, 1995. 


\section{NOTES}

